\title{
Twelve Novel Atm Mutations Identified in Chinese Ataxia Telangiectasia Patients
}

\author{
Yu Huang $\cdot$ Lu Yang $\cdot$ Jianchun Wang $\cdot$ \\ Fan Yang $\cdot$ Ying Xiao $\cdot$ Rongjun Xia $\cdot$ \\ Xianhou Yuan $\cdot$ Mingshan Yan
}

Received: 17 April 2013/Accepted: 14 June 2013/Published online: 27 June 2013

(C) The Author(s) 2013. This article is published with open access at Springerlink.com

\begin{abstract}
Ataxia telangiectasia (A-T) is an autosomal recessive disease characterized mainly by progressive cerebellar ataxia, oculocutaneous telangiectasia, and immunodeficiency. This disease is caused by mutations of the ataxia telangiectasia mutated (Atm) gene. More than $500 \mathrm{Atm}$ mutations that are responsible for A-T have been identified so far. However, there have been very few A-T cases reported in China, and only two Chinese A-T patients have undergone Atm gene analysis. In order to systemically investigate $\mathrm{A}-\mathrm{T}$ in China and map their Atm mutation spectrum, we recruited eight Chinese A-T patients from six unrelated families nationwide. Using direct sequencing of genomic DNA and the multiplex ligation-dependent probe amplification, we identified twelve pathogenic Atm mutations, including one missense, four nonsense, five frameshift, one splicing, and one large genomic deletion. All the Atm mutations we identified were novel, and no homozygous mutation and founder-effect mutation were found. These results suggest that Atm mutations in Chinese populations are diverse and distinct largely from those in other ethnic areas.
\end{abstract}

Y. Huang

Department of Medical Genetics, Peking University Health

Science Center, Beijing, China

L. Yang $\cdot$ J. Wang $\cdot$ F. Yang $\cdot$ Y. Xiao $\cdot$ R. Xia $\cdot$ X. Yuan ·

M. Yan $(\bowtie)$

Zijing Biomedical Institute, School of Medicine,

Wuhan University of Science and Technology,

820 Heping Street, Wuhan 430062, China

e-mail: mingshanyan@yahoo.com

M. Yan

Bach Pharma, Inc., 800 Turnpike Street, Suite 300,

North Andover, MA 01845, USA
Keywords Ataxia telangiectasia - Mutation analysis . Sequencing - MLPA

\section{Introduction}

The hallmark of A-T is progressive neurodegeneration, manifested as cerebellar ataxia (Boder et al. 1958; Barlow et al. 1996). A-T occurs in early childhood, with an incidence varying from 1 in 40,000 to 100,000 births in various ethnic areas (Swift et al. 1986), and caused by biallelic mutations of Atm gene located on chromosome 11q23.1 (Gatti et al. 1988). Atm gene, identified in 1995 (Savitsky et al. 1995), is very large and is comprised of 66 exons with an open reading frame of 9,168 nucleotides. Atm gene product, ATM, is a protein kinase with 3,050 amino acids and belongs to the phosphoinositide 3-kinase-related protein kinase super family. ATM is mainly located in the nucleus, although it has been found in cytosol associated with peroxisomes (Watters et al. 1999). As a multifunctional protein kinase, ATM, upon its autophosphorylation, plays a critical role in regulation of cell cycle control, DNA damage and repair, and cell survival and death by orchestrating the phosphorylation of multiple substrates (Goodarzi et al. 2004; Kozlov et al. 2011). As a caretaker, ATM, which also is a redox thiol-sensitive protein kinase, functions by activating multiple redox-sensitive or phosphorylationsensitive mechanisms responsible for maintaining genomic, telomeric, and chromosomal integrity under conditions of genomic or redox stress primarily during postnatal development (Barlow et al. 1999; Yan et al. 2001; Yan et al. 2006). Recently, a large-scale proteomic analysis of protein phosphorylation in response to DNA damage revealed that more than 700 proteins and 900 phosphorylation sites were correlated with ATM and ATR (ataxia telangiectasia and Rad3-related) (Matsuoka et al. 2007). 
To date, more than 500 Atm mutations have been identified as the disease-causing mutations (http://www. hgmd.cf.ac.uk/ac/gene.php?gene=ATM). The mutations can be found in every exon with no apparent hotspots. The majority of Atm mutations are frameshift or nonsense mutations (Wright et al. 1996; Concannon and Gatti 1997), which are predicted to truncate the whole ATM protein. Other Atm mutations include missense mutation, splicing, and large genomic deletion/duplication, etc.

In China, less than $30 \mathrm{~A}-\mathrm{T}$ patients have been reported by different hospitals, and only two unique Atm mutations have been identified so far (Jiang et al. 2006). This calls a question whether the incidence of $\mathrm{A}-\mathrm{T}$ in Chinese population is lower than that in other countries or the A-T cases are technically misdiagnosed there. Therefore, it is urgent to study Chinese A-T, including Atm mutation analysis. In the present study, we screened 12 novel Atm mutations in 8 Chinese A-T patients from 6 unrelated families. Our results showed an inkling that Atm mutations in Chinese A-T patients are diverse, which, in turn, make it possible to better identify individual A-T patients who are suitable for future customized mutation-targeted therapies based on their Atm mutated status.

\section{Materials and Methods}

\section{Patients}

Eight A-T patients from 6 unrelated families were recruited from 5 different provinces of China. The primary clinical diagnosis for those A-T patients was mainly based on the presence of progressive neurodegeneration as shown by cerebellar ataxia and cerebellar atrophy, telangiectasia, elevated serum levels of alpha-fetoprotein, and altered serum levels of immunoglobulins. The clinical features of the individual A-T patients were summarized in Table 1. All families signed the informed consent for this study.

\section{Mutation Screening}

Blood samples were collected from each A-T patients and their parents for mutation analysis, which includes the entire Atm gene coding sequence, adjacent intron regions and $3^{\prime} \mathrm{UTR}$ and $5^{\prime} \mathrm{UTR}$, and performed by direct sequencing of PCR products as described previously (Soukupova et al. 2011).

The large genomic rearrangements in the Atm locus were tested for all patients with the multiplex ligationdependent probe amplification (MLPA). MLPA is a reliable technology for relatively quantitative analysis of the copy number in clinical diagnosis of genetic diseases. An MLPA kit with probes of P041 and P042 for detecting the deletion and/or duplication of the Atm gene was purchased from MRC Holland (Amsterdam, Netherlands). Procedures were performed according to the manufacturer's instruction. In brief, ligation and amplification were carried out with an ABI 9800 Thermal Cycler. The PCR conditions were 35 cycles at $95{ }^{\circ} \mathrm{C}$ for $30 \mathrm{~s}, 60{ }^{\circ} \mathrm{C}$ for $30 \mathrm{~s}$, and $72{ }^{\circ} \mathrm{C}$ for $60 \mathrm{~s}$, followed by a final incubation at $72{ }^{\circ} \mathrm{C}$ for 20 min. The PCR products were separated by capillary electrophoresis in an ABI 3700 Genetic Analyzer (Applied Biosystems, Foster City, California). The raw data were analyzed by GeneMarker v1.5 software. The peaks obtained after the analysis of DNA fragments could be distinguished and assigned to specific exons on the basis of their different lengths representing the variability of their stuffer sequences. Peak area of raw data was then exported into a Microsoft Excel spreadsheet program to normalize each peak with known normal controls. Peaks derived from A-T patients that vary more than $20 \%$ from the normal controls should be flagged for review. If a deletion of single exon was observed, conventional PCR with primers of the exon was performed to verify the deletion.

\section{Results}

As shown in Table 1, all A-T patients (CHATs) had the typical symptoms of ataxia and telangiectasia, sign of cerebellar atrophy by CT and MRI examinations, and elevated serum alpha-fetoprotein. Immunodeficiency is also one of the major characteristics of A-T. In our Chinese A-T patient cohort, 5 out of 8 patients $(62.5 \%)$ had normal or slightly decreased serum levels of $\operatorname{IgG}, \operatorname{IgA}$, and $\operatorname{IgM}$. Those configurations were in agreement with the clinical records and patient descriptions that those (CHAT 3, 4, 5, 6 and 8) with relative normal levels of serum immunoglobulins had no histories of repeat sinopulmonary infections, while others (CHAT1, 2 and 7) with agammaglobulinemia often suffered from such infection with fever and had to receive gammaglobulin injection termly. None of the eight A-T patients had sign of being developed a malignancy.

The genetic analysis of Atm gene identified 12 diseasecausing mutations in 6 unrelated A-T families (Table 2). The mutation types are diverse, including 4 nonsense (33.3\%), 1 splicing (8.3\%), 5 frameshift (42\%), 1 large genomic deletion (8.3\%), and 1 missense mutation (8.3). All the Atm mutations were novel. Interestingly, a nonsense mutation c. $1464 \mathrm{G}>\mathrm{A}$ in family 1 shared same resultant protein effect of $\mathrm{p} . \mathrm{W} 448 \mathrm{X}$ with a previously reported nonsense mutation c. $1463 \mathrm{G}>\mathrm{A}$ in an Italian A-T patient (Cavalieri et al. 2006). That is because c.1464G $>A$ results in a premature stop code TGA while c. $1463 \mathrm{G}>\mathrm{A}$ results in a premature stop code TAG. No founder-effect mutation of 
Table 1 Major clinical and laboratory features of Chinese A-T Patients (CHAT)

${ }^{a}$ Range of blood alphafetoprotein normal value: $0-20 \mathrm{ng} / \mathrm{ml}$

b Range of blood IgG normal value: $7-17 \mathrm{~g} / \mathrm{l}$

${ }^{c}$ Range of blood IgA normal value: $0.72-4.29 \mathrm{~g} / 1$

${ }^{\mathrm{d}}$ Range of blood IgM normal value: $0.6-2.6 \mathrm{~g} / \mathrm{l}$

e Range of blood IgE normal value: $0-200 \mathrm{KIU} / \mathrm{l}$

\begin{tabular}{|c|c|c|c|c|c|c|c|c|c|c|}
\hline \multirow[t]{2}{*}{ Patient } & \multirow[t]{2}{*}{ Sex } & \multirow[t]{2}{*}{ Age } & \multirow{2}{*}{$\begin{array}{l}\text { Ataxia- } \\
\text { age at } \\
\text { onset } \\
\text { (month) }\end{array}$} & \multirow{2}{*}{$\begin{array}{l}\text { Telangiectasia- } \\
\text { age at onset } \\
\text { (year) }\end{array}$} & \multirow{2}{*}{$\begin{array}{l}\text { Cerebellar } \\
\text { atrophy }\end{array}$} & \multirow{2}{*}{$\begin{array}{l}\text { Alpha- } \\
\text { fetoprotein } \\
\left(\mathrm{ng} / \mathrm{ml}^{\mathrm{a}}\right.\end{array}$} & \multicolumn{4}{|c|}{ Immunoglobulins } \\
\hline & & & & & & & $\begin{array}{l}\mathrm{IgG} \\
(\mathrm{g} / \mathrm{l})^{\mathrm{b}}\end{array}$ & $\begin{array}{l}\mathrm{IgA} \\
(\mathrm{g} / \\
1)^{\mathrm{c}}\end{array}$ & $\begin{array}{l}\operatorname{IgM} \\
(\mathrm{g} / \\
1)^{\mathrm{d}}\end{array}$ & $\begin{array}{l}\mathrm{IgE} \\
(\mathrm{KIU} / \\
1)^{\mathrm{e}}\end{array}$ \\
\hline CHAT1 & $\mathrm{F}$ & 13 & 24 & 3 & Atrophied & 554 & 2.68 & 0.02 & 1.1 & $<0.1$ \\
\hline CHAT2 & $\mathrm{F}$ & 4 & 18 & 2 & Atrophied & 142 & 4.2 & 0.01 & 1.5 & $<0.1$ \\
\hline СНAT3 & $\mathrm{F}$ & 14 & 30 & 3 & Atrophied & 651 & 14.4 & 0.24 & 2.47 & 0 \\
\hline CHAT4 & $\mathrm{F}$ & 7 & 18 & 1 & Atrophied & 164 & 8.9 & 0.5 & 1.26 & 0 \\
\hline CHAT5 & $\mathrm{F}$ & 13 & 48 & 1 & Atrophied & 325 & 8.8 & 1.17 & 1.07 & 2.95 \\
\hline CHAT6 & M & 8 & 18 & 2 & Atrophied & 170 & 7.8 & 0.9 & 1.85 & 0 \\
\hline CHAT7 & M & 8 & 24 & 2 & Atrophied & 69 & 3.5 & 0.15 & 1.2 & $<0.1$ \\
\hline СНAT8 & $\mathrm{F}$ & 7 & 24 & 2 & Atrophied & 251 & 7.72 & 0.7 & 0.8 & 0.12 \\
\hline
\end{tabular}

Table 2 Atm Mutations of eight patients from six families

\begin{tabular}{|c|c|c|c|c|c|c|}
\hline Family & Patient & Mutations & Allele & Location & Type & Protein effect \\
\hline \multirow[t]{2}{*}{1} & \multirow[t]{2}{*}{ CHAT1/2 } & c. $1464 \mathrm{G}>\mathrm{A}$ & $\mathrm{Ma}$ & Exon10 & Nonsense & p.W448X \\
\hline & & ins $56-1 \mathrm{G}>\mathrm{A}$ & $\mathrm{Pa}$ & Exon57 & Splicing & Splicing \\
\hline \multirow[t]{2}{*}{2} & \multirow[t]{2}{*}{ СHAT3/4 } & c.2680delG & $\mathrm{Ma}$ & Exon18 & Frameshift & p.D894IfsX4 \\
\hline & & c. $7166 \mathrm{C}>\mathrm{G}$ & $\mathrm{Pa}$ & Exon49 & Nonsense & p.S2389X \\
\hline \multirow[t]{2}{*}{3} & \multirow[t]{2}{*}{ CHAT5 } & c. $3174 \mathrm{G}>\mathrm{A}$ & $\mathrm{Ma}$ & Exon22 & Nonsense & p.W1058X \\
\hline & & Exon 63 deletion & $\mathrm{Pa}$ & Exon63 & large genomic deletion & N/A \\
\hline \multirow[t]{2}{*}{4} & \multirow[t]{2}{*}{ CHAT6 } & c.2152_2154delinsAAAC & $\mathrm{Ma}$ & Exon14 & Frameshift & p.C718KfsX19 \\
\hline & & c.8713_8714insCA & $\mathrm{Pa}$ & Exon60 & Frameshift & p.V2906QfsX32 \\
\hline \multirow[t]{2}{*}{5} & \multirow[t]{2}{*}{ CHAT7 } & c1402_1403delAA & $\mathrm{Ma}$ & Exon10 & Frameshift & p.K468EfsX17 \\
\hline & & c. $2413 \mathrm{C}>\mathrm{T}$ & $\mathrm{Pa}$ & Exon16 & Nonsense & p.R805X \\
\hline \multirow[t]{2}{*}{6} & \multirow[t]{2}{*}{ CHAT8 } & c. $6885 \mathrm{G}>\mathrm{T}$ & $\mathrm{Ma}$ & Exon46 & Missense & p.V1248F \\
\hline & & c.3742_3743insGGAGGTTCT & $\mathrm{Pa}$ & Exon 25 & Frameshift & p.Y1248WfsX10 \\
\hline
\end{tabular}

Atm was found because 12 mutations were unique in each unrelated A-T families. In CHAT5, the large genomic deletion in exon 63 was detected in his paternal allele with MPLA method (Fig. 1), combined with a nonsense mutation c. $3174 \mathrm{G}>\mathrm{A}$ in exon 22 in his maternal allele (Table 2).

\section{Discussion}

Two novel Atm mutations in two unrelated Chinese A-T families were reported in 2006 (Jiang et al. 2006). One of them was a homozygous missense mutation, c.1346G $>C$, and another one was a compound heterozygous nonsense mutation, c. $610 \mathrm{G}>\mathrm{T}$, combined with a previously reported missense mutation, c.6679C $>\mathrm{T}$. In this study, we screened out 12 novel Atm mutations in 6 unrelated Chinese A-T families (Table 2).

The majority of Atm mutations are frameshift or nonsense mutations (Wright et al. 1996; Concannon and Gatti 1997; Li and Swift 2000). These mutations result in total loss of ATM protein and account in diagnosis for about $75 \%$ of A-T cases (Jacquemin et al. 2011). Despite the

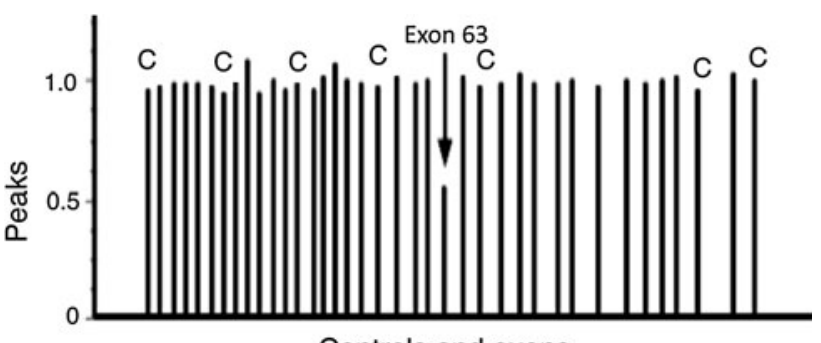

Controls and exons

Fig. 1 Normalized peak area histogram for LGD analysis in CHAT5. Seven bars with a capital $\mathrm{C}$ on the tops represent the signals of control samples, and other 31 bars represent the signals of exons detected with the MLPA P041 kit. The arrow indicates the decreased signal of exon 63 , corresponding to the genomic deletion

small number of A-T patients we examined, the frequencies of nonsense mutations (4 in 12) and frameshift (5 in 12) are very close to those previously reported (Concannon and gatti 1997).

Large genomic deletion (LGD) is a very rare Atm mutation type and had been estimated at $2 \%$ of the Atm 
mutations identified (Cavalieri et al. 2008). However, high frequency of LGD has recently been reported in Japan (Nakamura et al. 2011). Four out of 16 Atm mutations in Japanese A-T patients examined were LGDs. There has been no report showing that LGD occurs in a homozygous state in A-T patients (Mitui et al. 2003). In our cases, a LGD in exon 63 was found in CHAT5 whose another mutation was nonsense mutation (c.3174G $>$ A) in exon 22 . Atm missense mutations have been shown to cause either typical or milder phenotypes (Verhagen et al. 2009). A recent study showed that most Atm missense mutations in A-T are functionally associated with expression defects and/or inactivation of ATM protein kinase (Barone et al. 2009). Jacquemin et al. demonstrated that, in addition to causing ATM protein underexpression (15 out of 16 cases), most Atm missense mutations exhibited abnormal cytoplasmic localization of ATM (Jacquemin et al. 2011). Among the 12 mutations found in our A-T patients, only one missense mutation in exon 46 combined with a frameshift in exon 25 was identified in CHAT8 whose clinical features of A-T is typical. Together, our results revealed that most Atm mutation types, including nonsense, framshift, splicing, missense, and LGD, exist in Chinese A-T patients and that the individual mutations are diverse and distinct largely from those in other ethnic areas.

Although there has been no cure for A-T patients so far, the mutation-targeted therapeutic approaches have recently been developed rapidly, bringing hope of potential treatment for some A-T patients who carry Atm mutations suitable for correction by either antisense morpholino oligonucleotide (AMO) or readthrough compound (RTC) (Nakamura et al. 2011). AMOs can effectively correct type II and IV splicing mutations (Eng et al. 2004). Nakamura et al. showed that, using a designed AMO-j11 to treat an A-T cell line, the mutant splicing was abrogated in a dose-dependent manner and the full length ATM protein reappeared in the nuclear extracts from the cells (Nakamura et al. 2011). It has been shown that functional ATM protein can be induced with RTCs towards the premature termination codons in cells with an Atm heterozygous nonsense mutation (Du et al. 2009). Using a new designed RTC13, IR-activated ATM autophosphorylation at S1981 was measured in a human A-T lymphoblast cell line (Nakamura et al. 2011). These in vitro studies shed light on clinical application of the customized mutation-targeted therapies for A-T patients in the future. However, this personalized approach basically relies on Atm mutation analysis.

Acknowledgments We thank Dr. Ruifeng Guo for his critical review on this manuscript. This work was supported in part by grants from Zijing medical group and the Longevity Foundation at Austin, Texas. Moreover, we are grateful to the extended Howard family in Austin, Texas, and Dr. Paul KY Wong and Dr. Xianghong Kuang at MD. Anderson Cancer Center for their moral and scientific commitment to A-T research and to us.
Conflict of interest The authors declare no conflict of interest.

Open Access This article is distributed under the terms of the Creative Commons Attribution License which permits any use, distribution, and reproduction in any medium, provided the original author(s) and the source are credited.

\section{References}

Barlow, C., Dennery, P. A., Shigenaga, M. K., et al. (1999). Loss of the ataxia-telangiectasia gene product causes oxidative damage in target organs. Proceedings of the National Academy of Sciences of the United States of America, 96, 9915-9919.

Barlow, C., Hirotsune, S., Paylor, R., et al. (1996). Atm-deficient mice: A paradigm of ataxia telangiectasia. Cell, 86, 159-171.

Barone, G., Groom, A., Reiman, A., et al. (2009). Modeling ATM mutant proteins from missense changes confirms retained kinase activity. Human Mutation, 30, 1222-1230.

Boder, E., \& Sedgwick, R. P. (1958). Ataxia-telangiectasia; a familial syndrome of progressive cerebellar ataxia, oculocutaneous telangiectasia and frequent pulmonary infection. Pediatrics, 21, 526-554.

Cavalieri, S., Funaro, A., Pappi, P., et al. (2008). Large genomic mutations within the ATM gene detected by MLPA, including a duplication of $41 \mathrm{~kb}$ from exon 4 to 20. Annals of Human Genetics, 72(1), 10-18.

Cavalieri, S., Funaro, A., Porcedda, P., et al. (2006). ATM mutations in Italian families with ataxia telangiectasia include two distinct large genomic deletions. Human Mutat, 27, 1061.

Concannon, P., \& Gatti, R. A. (1997). Diversity of ATM gene mutations detected in patients with ataxia-telangiectasia. Human Mutation, 10, 100-107.

Du, L., Damoiseaux, R., Nahas, S., et al. (2009). Nonaminoglycoside compounds induce readthrough of nonsense mutations. Journal of Experimental Medicine, 206, 2285-2297.

Eng, L., Coutinho, G., Nahas, S., et al. (2004). Nonclassical splicing mutations in the coding and noncoding regions of the ATM Gene: Maximum entropy estimates of splice junction strengths. Human Mutation, 23, 67-76.

Gatti, R. A., Berkel, I., Boder, E., et al. (1988). Localization of an ataxia telangiectasia gene to chromosome 11q22-23. Nature, $336,577-580$

Gilad, S., Khosravi, R., Shkedy, D., et al. (1996). Predominance of null mutations in ataxia-telangiectasia. Human Molecular Genetics, 5, 433-439.

Goodarzi, A. A., Jonnalagadda, J. C., Douglas, P., et al. (2004). Autophosphorylation of ataxia-telangiectasia mutated is regulated by protein phosphatase 2A. EMBO Journal, 23, 4451-4461.

Jacquemin, V., Rieunier, G., Jacob, S., et al. (2011). Underexpression and abnormal localization of ATM products in ataxia telangiectasia patients bearing ATMmissense mutations. European Journal of Human Genetics, 20, 305-312.

Jiang, H., Tang, B., Xia, K., et al. (2006). Mutation analysis of the ATM gene in two Chinese patients with ataxia telangiectasia. Journal of neurological sciences, 241, 1-6.

Li, A., \& Swift, M. (2000). Mutations at the ataxia-telangiectasia locus and clinical phenotypes of A-T patients. American Journal of Medical Genetics, 92, 170-177.

Matsuoka, S., Ballif, B. A., Smogorzewska, A., et al. (2007). ATM and ATR substrate analysis reveals extensive protein networks responsive to DNA damage. Science, 316, 1160-1166.

Mitui, M., Campbell, C., Coutinho, G., et al. (2003). Independent mutational events are rare in the ATM gene: Haplotype prescreening enhances mutation detection rate. Human Mutation, 22, 43-50. 
Nakamura, K., Du, L., Tunuguntla, R., et al. (2011). Functional characterization and targeted correction of ATM mutations identified in Japanese patients with ataxia- telangiectasia. Human Mutation, 33, 198-208.

Savitsky, K., Bar-Shira, A., Gilad, S., et al. (1995). A single ataxia telangiectasia gene with a product similar to PI-3 kinase. Science, 268, 1749-1753.

Soukupova, J., Pohlreich, P., \& Seemanova, E. (2011). Characterisation of ATM mutations in Slavic Ataxia telangiectasia patients. NeuroMolecular Medicine, 13, 204-211.

Swift, M., Morrell, D., Cromartie, E., Chamberlin, A. R., et al. (1986). The incidence and gene frequency of ataxia-telangiectasia in the United States. American Journal of Human Genetics, 39, 573-583.

Verhagen, M. M., Abdo, W. F., Willemsen, M. A., et al. (2009). Clinical spectrum of ataxia- telangiectasia in adulthood. $\mathrm{Neu}$ rology, 73, 430-437.
Watters, D., Kedar, P., Spring, K., et al. (1999). Localization of a portion of extranuclear ATM to peroxisomes. Journal of Biological Chemistry, 274, 34277-34282.

Wright, J., Teraoka, S., Onengut, S., et al. (1996). A high frequency of distinct ATM gene mutations in ataxia-telangiectasia. American Journal of Human Genetics, 59, 839-846.

Kozlov, S. V., Graham, M. E., Jakob, B., et al. (2011). Autophosphorylation and ATM activation: Additional sites add to the complexity. World Journal of biological chemistry, 286, 9107-9119.

Yan, M., Qiang, W., Liu, N., Shen, J., Lynn, W. S., \& Wong, P. K. (2001). The ataxia-telangiectasia gene product may modulate DNA turnover and control cell fate by regulating cellular redox in lymphocytes. The FASEB Journal, 15, 1132-1138.

Yan, M., Zhu, C., Liu, N., et al. (2006). ATM controls c-Myc and DNA synthesis during postnatal thymocyte development through regulation of redox state. Free radical biology and medicine, 41, 640-648. 